\title{
THE SPATIOTEMPORAL LAND USE/COVER CHANGE of ADANA CITY
}

\author{
A. Akın ${ }^{\text {a }}$, M. A. Erdoğan ${ }^{\text {b }, ~ S . ~ B e r b e r o g ̆ l u c ~}$ \\ ${ }^{a}$ Bursa Technical University, Urban and Regional Planning Department, Bursa - anil.tanriover@btu.edu.tr \\ ${ }^{\mathrm{b}}$ Cukurova University, Vocational School of Technical Sciences, Architecture and Urban Planning Dept., Program of \\ Geographic Information Systems, Adana - maerdogan@cu.edu.tr \\ ${ }^{c}$ Çukurova University, Landscape Architecture Department, Adana - suha@cu.edu.tr
}

KEY WORDS: Remote sensing, Change detection, Landscape metrics, SLEUTH model

\section{ABSTRACT:}

The major driving factors for land use planning are largely limited to socio-economic inputs that do not completely represent the spatio-temporal patterns and ecological inputs have often been neglected. Integration of remote sensing and GIS techniques enabled successful applications in characterizing the spatiotemporal trends of land use/land cover (LULC) change.

This study demonstrated an approach that combines remote sensing, landscape metrics, and LULC change analysis as a promising tool for understanding spatiotemporal patterns of Adana city. Calculation of spatial metrics was based on a categorical, patch-based representation of the landscape. Landscape metrics are conceptual framework for sustainable landscape and ecological planning. LULC change analysis was performed by considering the metric calculation. Post-classification technique was used for the metric based change detection and two different remotely sensed data set recorded in 1967 (CORONA) and 2007 (ALOS AVNIR) were used for the analysis. Additionally, a LULC projection for the year 2023 was also generated and integrated to the change analysis. SLEUTH model was utilised as a urban growth model for the future developments of study area in the scope of Cellular Automata (CA). SLEUTH model contains the main elements that characterize the core characteristics of CA: it works in a grid space of homogeneous cells, with a neighburhood of eight cells, two cell states and five transition rules that act in sequential time steps.

Most useful and relevant metrics for landscape including: percentage of landscape, patch density, edge density, largest patch index, Euclidian mean nearest neighbor distance, area weighted mean patch fractal dimension and contagion were calculated for the 1967, 2007 and 2023 LULC maps and temporal changes were determined for the study area. Most considerable change was observed on the agricultural areas. Urban sprawl is the major driving factor of the LULC change.

\section{INTRODUCTION}

The dynamic process of urbanization has led to fundamental changes resulting in various impacts on the structure, functions, and dynamics of ecological systems at a wide range of scales (Luck and Wu, 2002; Charles et al., 2005; Ji et al., 2006). Remote sensing techniques have advantages in characterizing the spatiotemporal trends of urban sprawl using multi-stage images, providing a basis for projecting future urbanization processes. Such information can support policymaking in urban planning and natural resource conservation. For the study spatial metrics were used for the analysis of spatial distributions and structural characteristics of urban land use. Spatial metrics are measurements derived from the digital analysis of thematic maps to show spatial heterogeneity at a specific scale and resolution (Herold et al., 2002). Such analyses provide quantitative characterizations of the spatial composition and configurations of habitat or land cover types, and can be used to track changes in landscape patterns over time (Henebry and Goodin, 2002). Its use has become a trend in urban change studies. Prediction LULC maps for the year 2023 was also was also generated and integrated to the metric calculation and change analysis. Cellular Automata (CA) approach with SLEUTH model was used for the future modelling. The family of models called CA is commanding greater attention all over the world and is a simple and effective tool to capture and simulate the complexity in dynamic systems (Silva and Clarke, 2005). SLEUTH is the evolutionary product of the Clarke Urban Growth Model that uses cellular automata, terrain mapping and land cover deltatron modeling to address urban growth (Gigalapolis, 2004). The main objective of this study is to evaluate and simulate urban land use process accurately in by using landscape metrics from 1967 to 2023 for the Adana city.

\section{MATERIAL AND METHOD}

\subsection{Study area}

Geographically, Adana is located at the Southeastern Mediterranean coast of Turkey. The latitudes and longitudes are $36^{\circ} 00^{\prime}-37^{\circ} 30^{\prime}$ and $34^{\circ} 30^{\prime}-36^{\circ} 00^{\prime}$ respectively. The city is situated on the River Seyhan, 30 kilometers inland from the Mediterranean Sea. Adana Province has a population of 1.56 million, making it the fifth most populous city in Turkey (Fig. 1 ). The southern part of the province is entirely flat with various crops such as citrus, vegetable, maize, cotton and wheat.

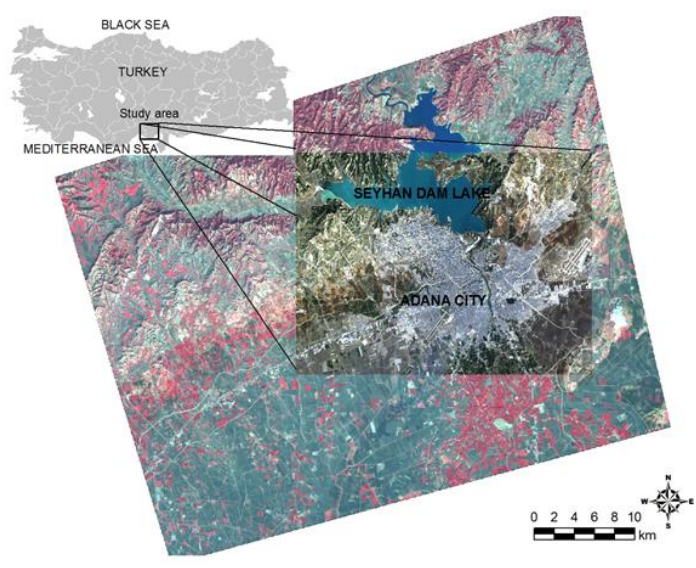

Figure 1. Study area 


\subsection{Material}

The data was given in the table 1 . Input data with high spatial resolution was resampled to common scale of $10 \mathrm{~m}$ common spatial resolution by using Nearest Neighbor and Cubic Convolution (spatial variables) methods.

Table 1. Remotely sensed dataset.

\begin{tabular}{llc}
\hline Date of acquisition & Data Source & $\begin{array}{c}\text { Spatial } \\
\text { resolution }\end{array}$ \\
\hline 18 August 1967 & Corona satellite photo & $2-4 \mathrm{~m}$ \\
22 February 2007 & ALOS AVNIR-2 & $10 \mathrm{~m}$ \\
\hline
\end{tabular}

\subsection{Method}

This study can be summarized into four phases as: (i) LULC maps derived from object based classification approach, (ii) preparation of the spatial variables for modeling, (iii) model calibration, validation and predicting urban development for the year 2023, (iv) metric calculation and change analysis.

\subsubsection{Object-based classification}

The object-based classification approach involves the integration of vector and raster data within a GIS environment and this approach enabled the extraction of image object primitives at different spatial resolutions, termed multiresolution segmentation. (Bian and Walsh 1992).

The next stage involved a supervised object based classification with the nearest neighbor algorithm. Each image object was assigned to settlement, agriculture, citrus, forest, bare ground, green belt, water and road classes (Fig. 2).

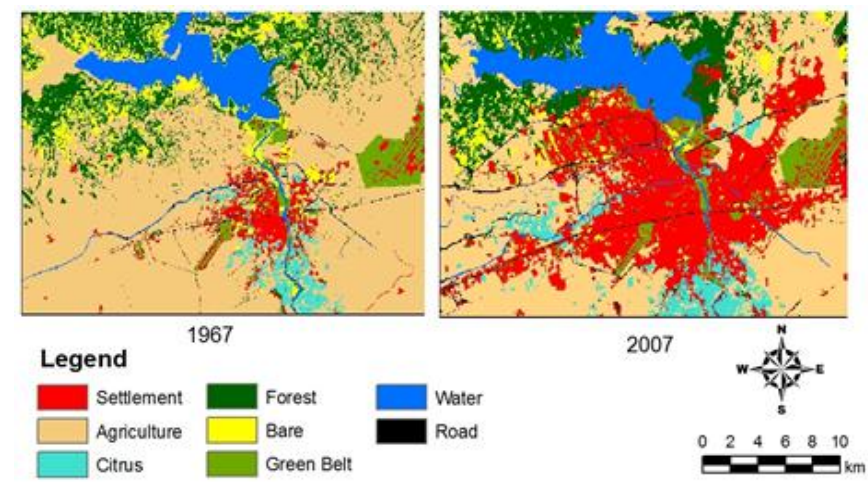

Figure 2.Object-based classification results.

\subsubsection{Cellular Automata and SLEUTH Model}

CA systems usually consists of four elements - cells, states, neighborhoods and rules. Cells are the smallest units which must manifest some adjacency or proximity. The state of a cell can change according to transition rules which are defined in terms of neighborhood functions. CA models are not only a framework for dynamic spatial modeling but a paradigm for thinking about complex spatial-temporal phenomena and an experimental laboratory for testing ideas (Itami, 1994). SLEUTH (Slope, Landuse, Excluded layer, Urban extent, Transportation, and Hillshade) model is adopted for the study area in the frame of CA approach.

The SLEUTH model is capable of modeling the complex urban growth dynamics or land use change system given a set of historical input data in a desired spatial resolution as a physical process using CA (Clarke and Gaydos 1998). Five factors control the behavior of the system: diffusion, breed, spread, slope resistance and road-gravity, each given a parameter from 0 to 100 . Besides this, four types of growth are defined in the model: spontaneous, diffusive, organic, and road influenced growth. Spontaneous growth defines the occurrence of random urbanization of land. This means that any unurbanized cell on the lattice has a certain (small) probability of becoming urbanized in any time step. New Spreading Center growth determines whether any of the new, spontaneously urbanized cells will become new urban spreading centers Organic or edge growth defines the growth that stems from existing spreading centers. This growth propagates both the new centers generated in New Spreading Center growth step, and the more established centers from earlier times. Road-Influenced growth is determined by the existing roads as well as the most recent urbanization (Silva \& Clarke, 2002, Oğuz, 2004).

The name SLEUTH was derived from the simple image input requirements of the models: Slope, Land cover, Exclusion, Urbanization, Transportation, and Hillshade (Fig.3).

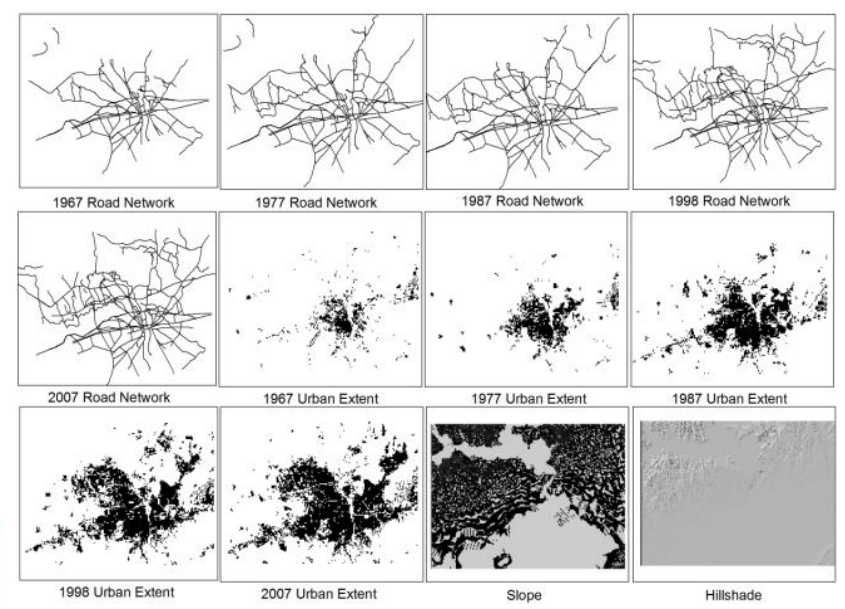

Figure 3. SLEUTH model Inputs

The calibration phase of modeling is one of the most critical steps of a modeling process. SLEUTH is a probabilistic model that uses Monte Carlo routines to generate multiple simulations of growth. During calibration, each simulation is compared with the control years within the time series, and averaged fit statistics are produced to measure the performance of a set of coefficient values in reproducing the observed urban development patterns.

\subsubsection{Landscape Metrics}

Landscape metrics are useful for monitoring landscape change over time as well as for comparing different landscapes (Turner, 1989). The basis of the spatial metric calculation is a thematic map representing a landscape comprised of spatial patches categorized in different patch classes (Herald et al., 2003).

Landscape metrics describe the spatial structure of a landscape at a set point in time. They provide information about the contents of the mosaic, e.g. the proportion of each landscape type or category present in the study area, or the shape of the component landscape elements (Leitao and Ahern, 2002).

For the study, landscape metrics were calculated using the software Fragstats 2.0 (McGarigal and Marks, 1994) for each individual image classification $(1967,2007,2023)$. 
To simplify interpretation, the following metrics were used (Forman, 1995; Grifith et al., 2000; Riitters et al., 1995, McGarigal et al., 2002; Dietzel et al., 2005a ).

(a) Percentage Land Cover (PLAND): Percentage of total area occupied by each class.

(b) Patch Density (PD): Percentage of patch number to total landscape area.

(c) Largest-Patch Index (LPI): Area of the largest patch in each class, expressed as a percentage of total landscape area.

(d) Edge Density (ED): Sum of length of all edge segments for the class, divided by total landscape area.

(f) Area Weighted Mean Patch Fractal Dimension (FRAC-AM): Area weighted mean value of the fractal dimension values of all patches of a land cover class.

(e) Contagion (CONTAG): Overall probability that a cell of a patch type is adjacent to cells of the same type.

(f) Mean Euclidian Nearest Neighbour Distance (ENN-MN): Mean of Euclidean geometry as the shortest straight-line distance between the focal patch and its nearest neighbour of the same class

\subsubsection{Change Analysis}

Change detection is the process of identifying differences in the state of an object or phenomenon by observing it at different times (Singh 1989). Timely and accurate change detection of Earth's surface features provides the foundation for better understanding relationships and interactions between human and natural phenomena to better manage and use resources $(\mathrm{Lu}$ et al., 2004). A variety of change detection techniques have been developed. Post-classification technique was selected for the study. Using the post classification comparison, land cover change is identified where the classification categories are found to be different between two or more image dates. The comparison results (i.e. pixels with 'change' status) are then assessed by a rule-based analysis based on both 'change/no change' and 'from-to' (land use shift) rationality (Liu and Zhou, 2004). Landscape metrics were evaluated in term of change detection and 2023 LULC map was integrated to the analysis.

\section{RESULTS}

\subsection{SLEUTH Model Results}

The model was calibrated using 3 different spatial resolutions, beginning with data of coarse resolution $(40 \mathrm{~m})$, narrowing the range of parameters that most accurately described the growth of the system, and then using a finer resolution (20m) to narrow the parameter values to one distinct set to use in the final calibration phase $(10 \mathrm{~m})$. Results from the three phases of the calibration mode (coarse, fine, final and drive) are presented in table 5 which presents the highest scores from model runs. In the coarse calibration, the resulting values were narrowed to $\{1$, $25,50,100,50\}$; and with fine calibration values with $\{1,25$, $60,50,25\}$ became more sensitive to local variation. In the final calibration, values became even became more sensitive to the finer details with the values of $\{1,24,62,48$, and 25 $\}$ (Fig. 4).

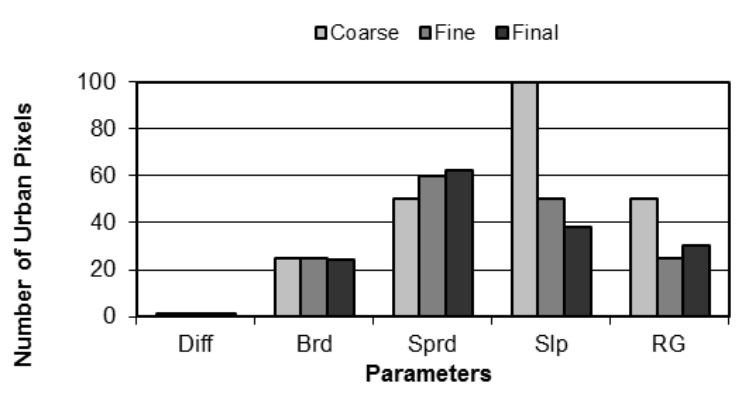

Figure 4. Urban growth response of different coefficiencies.

The comparison of the model final "population" (number of urban pixels) and the urbanization for the control years gave a high summary correlation of 0.99 and 0.89 respectively (compare_score) (Table 2). This means that the prediction of the model based on the initial seed year of the present urban pattern using those refined values is very similar to what happened in reality. The shape and form of urbanization seems that calibration adjusts the values to reflect local characteristics. The final calibration correlations are 0.64 in the case of the score r2_edges (modeled urban edges against the urban edges of control years), and 0.74 in the case of the cluster_r2 score (modeled number of urban clusters against known number of urban clusters). For the Lee-Sallee value (degree of shape match between the modeled growth and the known urban extent) 0.40 was achieved.

Table 2. Calibration results for SLEUTH

\begin{tabular}{llllllll}
\hline Scenario1 & Product & Compare & Pop & Edges & Cluster & $\begin{array}{l}\text { Cluster } \\
\text { Size }\end{array}$ & Leesalee \\
\hline Coarse & 0.006 & 0.97678 & 0.99147 & 0.7394 & 0.60499 & 0.90081 & 0.41352 \\
Fine & 0.02135 & 0.89927 & 0.9931 & 0.69567 & 0.75976 & 0.77954 & 0.40686 \\
Final & 0.03838 & 0.89453 & 0.99362 & 0.64 & 0.7428 & 0.75544 & 0.40249 \\
& Slope & $\%$ Urban & Xmean & Ymean & Rad & Fmatch & \\
\hline Coarse & 0.93925 & 0.99134 & 0.7234 & 0.94417 & 0.9905 & 0.58997 & \\
Fine & 0.81331 & 0.99269 & 0.73476 & 0.40451 & 0.99203 & 0.5991 & \\
Final & 0.87589 & 0.99326 & 0.70301 & 0.8262 & 0.99245 & 0.59566 & \\
& Diff & Brd & Sprd & Slp & RG & & \\
\hline Coarse & 1 & 25 & 50 & 100 & 50 & & \\
Fine & 1 & 25 & 60 & 50 & 25 & & \\
Final & 1 & 24 & 62 & 38 & 30 & & \\
Derive & 1 & 30 & 62 & 48 & 25 & & \\
\hline
\end{tabular}

It was observed that the impact of outward spread is more representative for Adana, on the other hand, diffusion accounts for far less growth (Fig.5). The urbanization of the metropolitan area tended to occur outward from the main nucleus and along the main transportation infrastructure. This explains why the spread_coefficient is as high as 62. However the lesser driving factor was reflected in the diffusion_coefficient. Creation of new nuclei on the open spaces was observed quite rarely. 


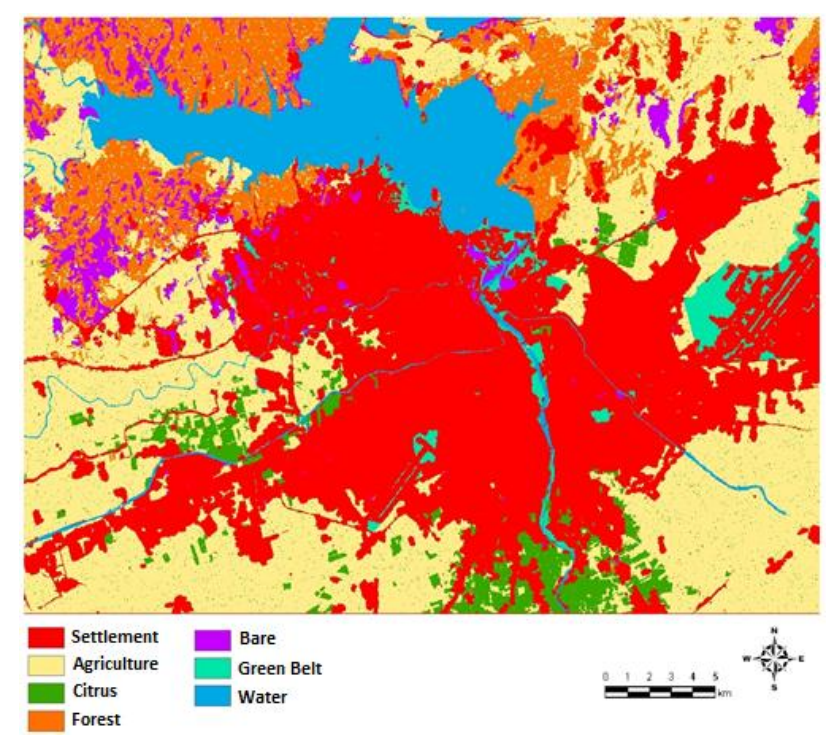

Figure 5. 2023 SLEUTH model prediction map.

\subsection{Metric Calculations}

The classified LULC of 1967 and 2007 also predicted LULC of 2023 are used as inputs for FRAGSTAT to calculate relevant landscape metrics for each class (Table 3).

Table 3. Landscape metric result of 1996, 2007 and 2023

\begin{tabular}{|c|c|c|c|c|c|c|c|c|}
\hline Metrics & Year & Settl. & Agric. & Citrus & Forest & Bare & $\begin{array}{r}\text { Green } \\
\text { Belt }\end{array}$ & Water \\
\hline \multirow{3}{*}{ PLAND } & 1967 & 5,13 & 60,38 & 2,25 & 13,13 & 8,13 & 3,54 & 7,44 \\
\hline & 2007 & 26,82 & 38,07 & 4,45 & 11,95 & 4,79 & 4,36 & 9,55 \\
\hline & 2023 & 36,91 & 34,29 & 3,42 & 10,60 & 3,49 & 1,80 & 9,49 \\
\hline \multirow{3}{*}{ PD } & 1967 & 8,72 & 4,30 & 0,40 & 8,51 & 4,86 & 1,60 & $\overline{1,03}$ \\
\hline & 2007 & 0,89 & 0,84 & 0,38 & 0,64 & 0,95 & 0,56 & 0,08 \\
\hline & 2023 & 0,53 & 3,80 & 1,30 & 0,93 & 0,87 & 0,49 & 0,38 \\
\hline \multirow{3}{*}{ LPI } & 1967 & 2,84 & 23,42 & 0,72 & 2,50 & 0,42 & 1,62 & $\overline{6,48}$ \\
\hline & 2007 & 17,21 & 8,37 & & 3,46 & & 1,35 & 8,28 \\
\hline & 2023 & 33,14 & 7,69 & 0,39 & 2,88 & 0,48 & 0,52 & 8,33 \\
\hline \multirow{3}{*}{ ED } & 1967 & 30,15 & 56,14 & 6,42 & 57,41 & 38,90 & 8,40 & $\overline{6,11}$ \\
\hline & 2007 & 34,75 & 29,19 & 7,62 & 18,23 & 15,48 & 10,33 & 6,37 \\
\hline & 2023 & 20,88 & 29,05 & 6,39 & 19,92 & 10,22 & 4,29 & 6,07 \\
\hline \multirow{3}{*}{ FRAC_AM } & 1967 & 1,35 & 1,31 & 1,22 & 1,33 & 1,26 & 1,21 & $\overline{1,19}$ \\
\hline & 2007 & 1,32 & 1,23 & 1,14 & 1,27 & 1,17 & 1,21 & 1,18 \\
\hline & 2023 & 1,27 & 1,22 & 1,14 & 1,29 & 1,16 & 1,14 & 1,18 \\
\hline \multirow{3}{*}{ CONTAG } & 1967 & 0,20 & 0,21 & 0,51 & 0,30 & 0,38 & 0,29 & 0,24 \\
\hline & 2007 & 0,74 & 0,78 & 0,88 & 0,79 & 0,82 & 0,74 & 0,83 \\
\hline & 2023 & 0,74 & 0,48 & 0,33 & 0,62 & 0,73 & 0,59 & 0,36 \\
\hline \multirow{3}{*}{ ENN_MN } & 1967 & 44,5 & 37,7 & 49,6 & 43,6 & 45,5 & 91,7 & $\overline{114,6}$ \\
\hline & 2007 & 129,3 & 134,0 & 270,4 & 219,4 & 140,3 & 185,7 & 114,3 \\
\hline & 2023 & 233,1 & 77,1 & 262,5 & 138,6 & 157,2 & 287,9 & 436,4 \\
\hline
\end{tabular}

Percentage of Land Cover (PLAND) will decrease for all classes except settlement which increased for the 1967-2007 time period and will be increasing till to 2023. The most significant decrease for PLAND is determined for agricultural areas (Figure 6).

Classes of settlement, forest, bare soil and green belt patch density (PD) values come out with decreases in their values. However agriculture, citrus and water classes have irregular pattern has a decrease for 1967-2007 time period and afterward increase for the year 2023 (Figure 7).

Largest-Patch Index (LPI) calculations indicate that the settlement class is growing and will be the biggest patch of this landscape for 2023. Inherently the other classes especially for the agricultural areas, largest patch size will decrease however this decline will be weak for classes of citrus, bare soil and green belt (Figure 8).

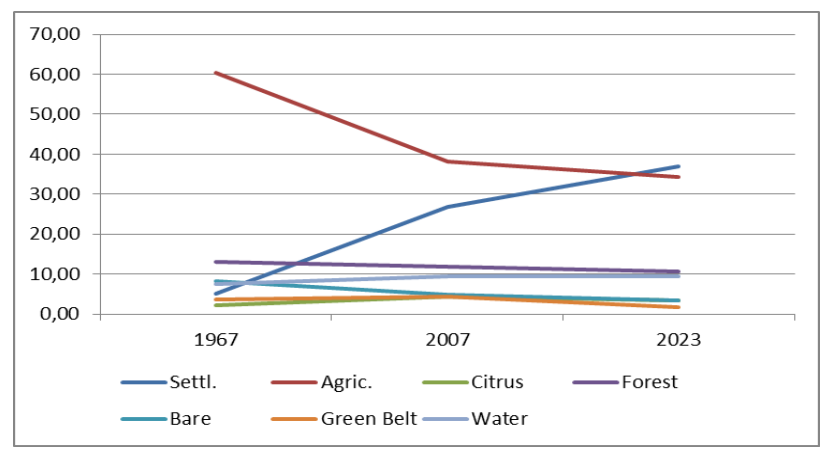

Figure 6. Percentage of Land Cover (PLAND) metrics.

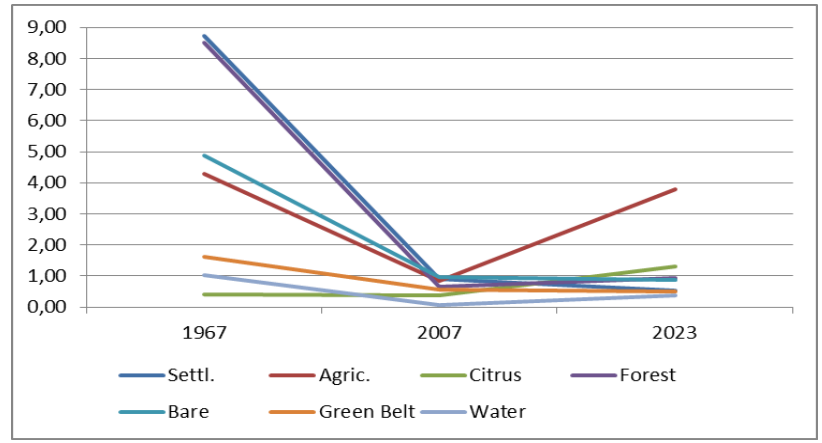

Figure 7. Patch Density (PD) metrics.

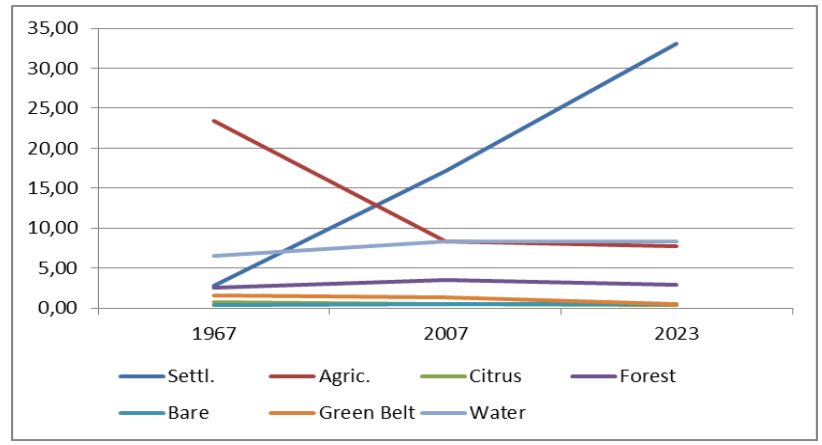

Figure 8. Largest-Patch Index (LPI) metrics.

Edge Density (ED) is an indicator for level of interaction among all classes. In this manner settlement ED was increased for 1967-2007 time period but there will be rapid decrease for 2023. This introduces that Adana will less sectional as a city and will be much poorer in terms of green belt. Agriculture, forest and bare ground classes will execute same pattern as ED parameters of settlement. These evidences emphasize that most of the classes will be compact and the Adana landscape will be more homogeneous (Figure 9).

The Area Weighted Mean Patch Fractal Dimension (FRACAM) describes the complexity and the fragmentation of a patch, by a perimeter-area comparison. All classes of the Adana landscape are in a trend of decrease in terms of FRAC-AM values. This figure out that all class patches will have been in a change of from more complex and fragmented form to compact quadrangular or rectangular form with relatively small perimeter relative to the area (Figure 10). 
The CONTAG calculation values of all classes increased for 1967-2007 time period. Hovever this increment turns down to decline for 2007-2023 time period. The Contagion Index (CONTAG) describes the fragmentation of a landscape so the city landscape became more fragment but it will be in a trend of beeing less fragment till to 2023 (Figure 11).

The calculation of Mean Euclidian Nearest Neighbour Distance (ENN-MN) metrics which attribute the scale of proximity of patches shows that settlement, bare soil and green belt have a growing value of ENN-MN which points out that these patches proximity will be decreasing. However for other classes, ENN$\mathrm{MN}$ values increased for 1967-2007 time period but a vice versa will happen for 2007-2023 (Figure 12). This can refer to the rapidly growing settlement that pushes other classes to its environment.

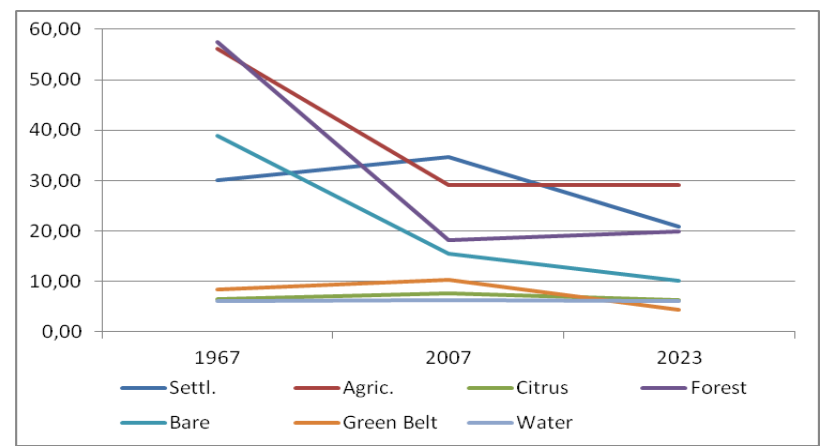

Figure 9. Edge Density (ED) metrics.

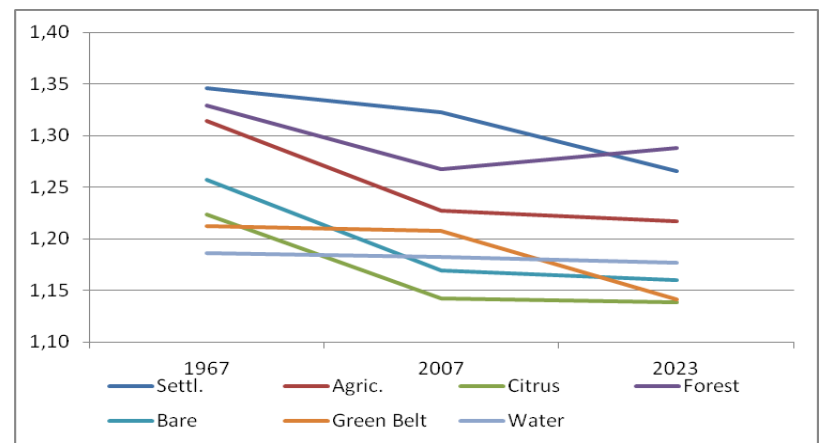

Figure 10. Area Weighted Mean Patch Fractal Dimension (FRAC-AM) metrics.

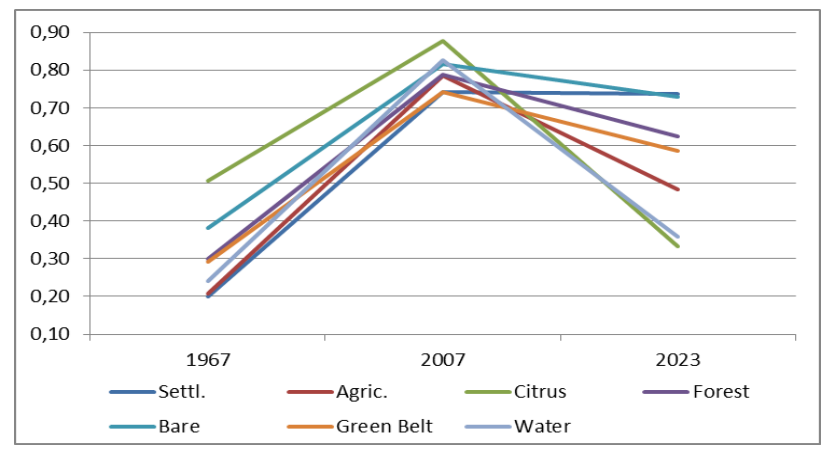

Figure 11. Contagion Index (CONTAG) metrics.

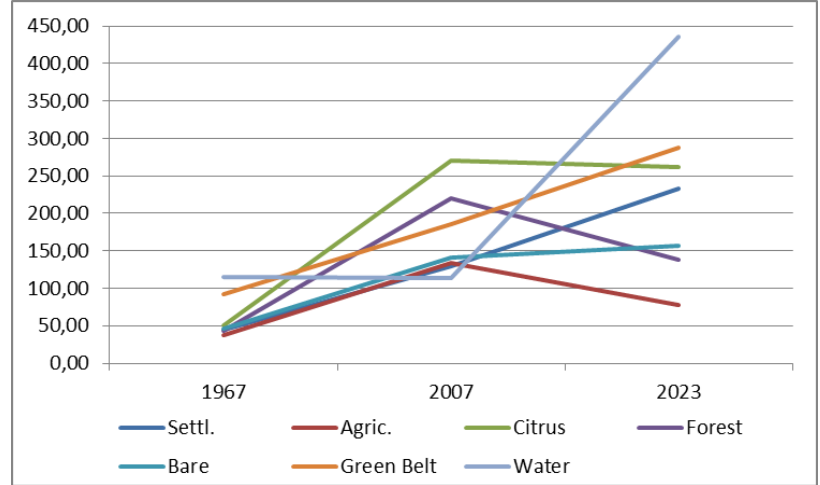

Figure 12. Mean Euclidian Nearest Neighbour Distance (ENN-MN) metrics.

\subsection{Change Analysis}

The change detection results showed that there is a growing trend toward urban areas at the expense of agricultural. Approximately $161 \mathrm{~km}^{2}$ of new urban area was gained mainly from the productive agricultural areas around the city center. By itself, $112 \mathrm{~km}^{2}$ of agriculture areas were converted primarily to urban and total of $145 \mathrm{~km} 2$ were lost in the defined time period. A second large urban transformation took place on the bare ground and green belts adding $27 \mathrm{~km}^{2}$ and $15 \mathrm{~km}^{2}$ of new urban area respectively (Fig.13).

The spatial prediction results for urban expansion showed that urban areas have been expanding continuously. The direction of expansion is along the existing urban areas and transportation routes.

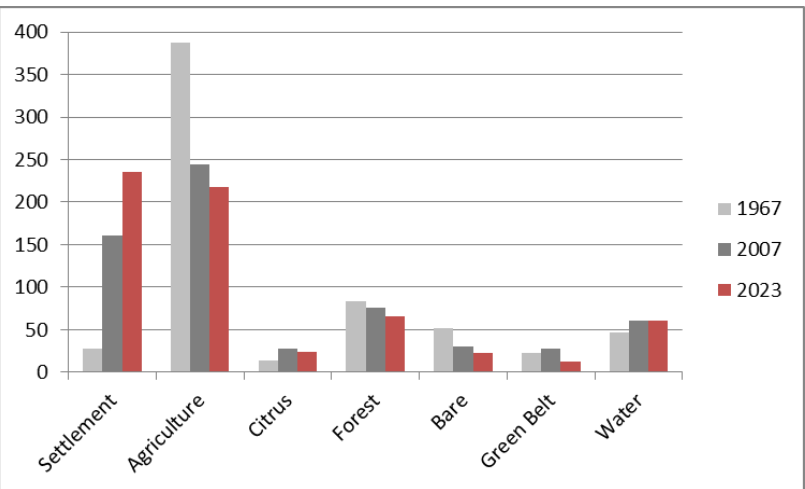

Figure 13. Area of change for 1967, 2007 and modeled 2023 (ha).

\section{CONCLUSIONS}

Adana has been under extensive development pressure since the beginning of the 1950s due to intense population growth. A vast amount of forest and semi-natural vegetation was converted to agriculture while even more agriculture was converted to urban areas. Growth was particularly strong in the west part of Adana. After the year 1998, the decrease in the growing rate can be clearly observed because of the environmental and agricultural growth policies.

Adana City is estimated as increasing in terms of heterogeneity and fragmentation of landscape metrics for 1967, 2007 and 2023.

Some of the outlines were summarized in the following: 
- The CORONA aerial photo which is used for 1967 classification has disadvantages as having distortions and being grey scale image. ALOS AVNIR with its spatial, spectral, radiometric and temporal resolution is find out as a suitable satellite image for medium-high resolution studies of land use/cover change detection and landscape metrics.

- The superiority of object-based classification over other classification approaches is highlighted with its manual correction option especially for classification error which are welded from satellite distortions.

- Post classification technique gives higher change detection accuracy results with the properly classified images. The classified images are accepted as the ground truth data after the extensive manual misclassification correction.

- Total PLAND, PD, LPI, ENN-MN, FRAC-AM metrics did not exhibit any harmonic behavior and they seem to provide important information about LULC evolution.

- The SLEUTH model was successfully calibrated for Adana using $10 \mathrm{~m}$ resolution data.

- SLEUTH model calibration and prediction results indicate a very high spread coefficient, which means that the growth characteristic in Adana is "organic" or edge growth. This is likely the case for most Turkish cities.

- One of the disadvantages for the SLEUTH model was that the calibration process as it was time consuming. Calibration was completed in two month time.

\section{References}

Bian, L., Walsh, S. J., 1992. Scale dependencies of vegetation and topography in mountainous environment of Montana. Professional Geographer 45, 1-11.

Dietzel, C, Herold, M, Hemphill, J. and Clarke, K C. , 2005. Spatio-temporal dynamics in California's Central Valley: Empirical links to urban theory', International Journal of Geographical Information Science, 19:2, 175 - 195.

Forman, R. T. T. ve Godron, M. 1986. Landscape Ecology. Wiley. New York. USA.

Gigalopolis, 2004. Project Gigalopolis: Urban and land cover modeling. Santa Barbara, CA: University of Santa Barbara at http://www.ncgia.ucsb.edu/projects/gig/.

Henebry, G.M., and D.G. Goodin, Landscape trajectory analysis: toward spatio-temporal models of biogeophysical fields for ecological forecasting. Paper presented at Workshop on Spatio-temporal Data Models for Biogeophysical Fields, La Jolla, CA.

Herold, M., Scepan, J., Clarke, K. C. 2002. The use of remote sensing and landscape-metrics to describe structures and changes in urban land uses. Environment and Planning A, 34, $1443-1458$.

Itami, R. M., 1994. Simulating spatial dynamics: cellular automata theory. Landscape and Urban Planning 30, 24- 47.

Ji, W. *, Ma, J. Twibell, R. Underhill, K. 2006. Characterizing urban sprawl using multi-stage remote sensing images and landscape metrics. Computers, Environment and Urban Systems, 30, 861-879.
Leitao, A. ve Ahern, J. 2002. Applying Landscape Ecological Concepts and Metrics in Sustainable Landscape Planning, Landscape and Urban Planning 59 (2002) 65- 93.

Lu, D.S., Mausel, P., Brondı'zio, E.S., Moran, E., 2004. Change detection techniques. International Journal of Remote Sensing 25, 2365-2407.

Luck, M. and J. Wu. 2002. A gradient analysis of the landscape pattern of urbanization in the Phoenix metropolitan area of USA. Landscape Ecology 17:327-339.

McGarigal, K., \& Marks, B. J. 1995. FRAGSTATS: spatial pattern analysis program for quantifying landscape structure. USDA Forest Service General Technical Report PNW-351.

MCGarıgal, K., Cushman, S.A., Neel, M.C. and Ene, E., 2002, FRAGSTATS: Spatial Pattern Analysis Program for Categorical Maps,www.umass.edu/landeco/research/fragstats/fragstats.html.

Oğuz, H. 2004. Modeling Urban Growth And Land Use/Land Cover Change In The Houston Metropolitan Area From 2002 2030. Doctor Of Philosophy. Texas A\&M University

Riitters, K. H., R. V. O'Neill, C. T. Hunsaker, J. D. Wickham, D. H. Yankee, S. P. Timmins, K. B. Jones, and B. L. Jackson. 1995. A factor analysis of landscape pattern and structure metrics. Landscape Ecol. 10: 23-40.

Silva, E. A., Clarke, C. K., 2005. Complexity, Emergence and Cellular Urban Models: Lessons Learned from Appling SLEUTH to two Portuguese Cities. European Planning Studies 13, 93-115.

Silva, E. A., Clarke, K. C., 2002. Calibration of the SLEUTH urban growth model for Lisbon and Porto, Portugal" Computers, Environment and Urban Systems 26, 525-552.

Singh, A., 1989. Digital change detection techniques using remotely sensed data. International Journal of Remote Sensing $10,989-1003$.

Turner, M.G., O’Neill, R.V., Gardner, R.H., Milne, B.T., 1989. Effects of changing spatial scale on the analysis of landscape pattern. Landsc. Ecol. 3,153-162. 